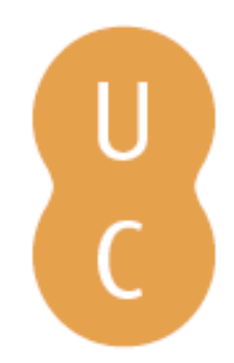

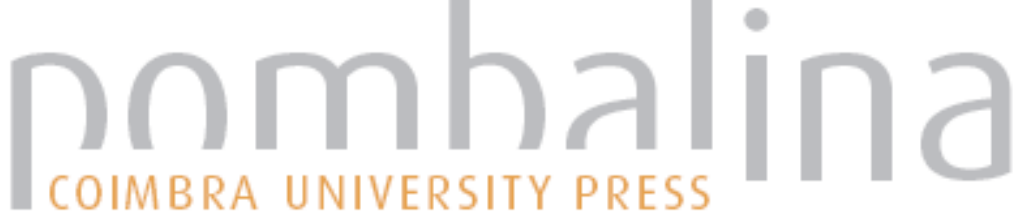

Habitos alimentares dos jesuítas em Portugal, na Índia e no Brasil (séc. XVI-XVIII)

Autor(es): Osswald, Cristina

Publicado por: Imprensa da Universidade de Coimbra

URL

persistente: URI:http://hdl.handle.net/10316.2/31581

DOI: $\quad$ DOI:http://dx.doi.org/10.14195/978-989-26-0201-1_3

Accessed : $\quad$ 26-Apr-2023 15:02:54

A navegação consulta e descarregamento dos títulos inseridos nas Bibliotecas Digitais UC Digitalis, UC Pombalina e UC Impactum, pressupõem a aceitação plena e sem reservas dos Termos e Condições de Uso destas Bibliotecas Digitais, disponíveis em https://digitalis.uc.pt/pt-pt/termos.

Conforme exposto nos referidos Termos e Condições de Uso, o descarregamento de títulos de acesso restrito requer uma licença válida de autorização devendo o utilizador aceder ao(s) documento(s) a partir de um endereço de IP da instituição detentora da supramencionada licença.

Ao utilizador é apenas permitido o descarregamento para uso pessoal, pelo que o emprego do(s) título(s) descarregado(s) para outro fim, designadamente comercial, carece de autorização do respetivo autor ou editor da obra.

Na medida em que todas as obras da UC Digitalis se encontram protegidas pelo Código do Direito de Autor e Direitos Conexos e demais legislação aplicável, toda a cópia, parcial ou total, deste documento, nos casos em que é legalmente admitida, deverá conter ou fazer-se acompanhar por este aviso.

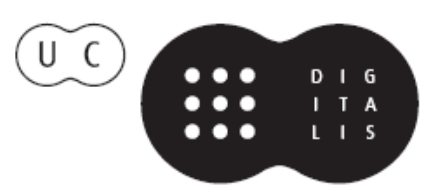


Isabel dos Guimarães Sá Máximo García Fernández (directores)

\section{PORTAS ADENTRO comer, vestir, habitar} (ss. XVI-XIX) 


\title{
HABITOS ALIMENTARES DOS JESUÍTAS EM PORTUGAL, NA ÍNDIA E NO BRASIL (SÉC. XVI-XVIII)
}

\author{
CRISTINA OsSWALD \\ Bolseira de pós-doutoramento da FCT. Departamento de História ${ }^{1}$ \\ Universidade do Minho
}

\section{INTRODUÇÃO-OS CONCEITOS DE «MODO NOSTRO»E «COMER Y BEBER NOSTRO»}

À semelhança das restantes actividades características da Companhia de Jesus, o assim denominado «Modo Nostro», a concepção e a organização do sistema alimentar jesuíta (organização da produção, preparação e distribuição dos alimentos e das bebidas), designado pelos mesmos como «Comer y Beber Nostro», estavam sujeitas a regras precisas. Todavia, em simultâneo, ao «Modo Nostro» estava inerente o conceito de flexibilidade ou acomodação aos diferentes contextos locais. Por essa razão, os responsáveis estavam interessados em tomar conhecimento, o mais detalhado possível, dos vários teatros onde actuavam os missionários, para assim melhor legislarem. Por outras palavras, a documentação jesuíta (cartas, normas, crónicas) constitui um manancial de informação vastíssimo e ainda pouco explorado sobre os hábitos quotidianos, incluindo os hábitos alimentares, das populações locais e dos recém- chegados habitantes das regiões, onde os membros da Companhia de Jesus viviam e trabalhavam.

De facto, a acomodação esteve sempre presente na concepção que os Jesuítas quiseram dar a si mesmos, e que teve amplos reflexos na prática. Neste sentido, um dos objectivos deste texto é analisar de que modo as dietas alimen-

${ }^{1}$ E na UNED (Madrid), e na UNICAMP (São Paulo, Brasil). Trabalho elaborado no âmbito do projecto Portas Adentro: modos de habitar do século XVI a XVIII em Portugal, financiado pela FCT (PTDC/HAH/71309/2006). 
tares dos Jesuítas podiam variar entre um contexto europeu (Portugal) e as missões fora da Europa, mais concretamente a Índia e o Brasil. Interessa reflectir, se as prováveis diferenças dos sistemas alimentares nestas três regiões se deveram sobretudo a uma estratégia de acomodação voluntária ou à necessidade. Terá, em alguns casos extremos, a tão propagada política ou estratégia de acomodação dos Jesuítas originado práticas alimentares não aceites pela hierarquia em Lisboa ou mesmo em Roma?

\section{ASPECTOS CARACTERÍSTICOS DO SISTEMA ALIMENTAR DOS JESUÍTAS EM PORTUGAL, NA ÍNDIA E NO BRASIL: PRODUÇÃO, PRIN- CIPAIS ORIGENS DOS BENS, DISTRIBUIÇÃO DE TAREFAS E HORÁ- RIOS}

Os responsáveis das várias instituições jesuítas em análise tinham, muitas vezes, de prover à alimentação, não apenas dos membros da comunidade, como duma série de outras pessoas. Eram os últimos, sobretudo, colaboradores externos (barbeiros, boticários), assim como, com frequência, convidados, e membros de outras instituições pertencentes ou não à Companhia de Jesus e ainda de grupos desfavorecidos, tais como pobres, enfermos e reclusos ${ }^{2}$.

Determinavam as prescrições internas da Companhia, que todas as províncias tivessem áreas rurais (as assim chamadas cercas) localizadas fora dos aglomerados urbanos, que deviam servir não apenas como áreas de lazer, como também enquanto principais fontes de abastecimento para as comunidades jesuítas nas cidades ${ }^{3}$.

Todavia, nem sempre as cercas ou hortas eram suficientes para prover em quantidade e qualidade as necessidades alimentares das comunidades jesuítas. Era necessário proceder-se à compra de produtos, como o peixe, o vinho, o azeite, os queijos produzidos localmente ou importados de outros países ${ }^{4}$.

Os Jesuítas beneficiaram, também neste contexto, da atribuição de inúmeros privilégios reais. Um alvará de D. Sebastião com a data de 5 de Maio de 1583 isentava os Jesuítas do Colégio do Funchal do pagamento das taxas alfandegá-

${ }^{2}$ No séc. XVII, os Jesuítas da Baía tinham por hábito oferecer anualmente um jantar solene aos reclusos. Ver S. Leite, Breve História da Companhia de Jesus no Brasil, Braga, Liv. A.I., 1993, p. 164.

${ }^{3}$ Dentro e fora de Portugal, algumas destas cercas desenvolveram-se em autênticos potentados agro-pecuários com capacidade para abastecer cidades inteiras, como aconteceu durante o cerco de S. Salvador da Bahia pelos holandeses em 1635. Ver D. Alden, The making of an enterprise: The Society of Jesus in Portugal, its Empire, and beyond 1540-1750, Stanford, University Press, 1996, p. 211. Brasil.

${ }^{4}$ À semelhança de Portugal Continental, os queijos flamengos eram muito apreciados no 
rias de bens alimentares enviados do Reino ${ }^{5}$. Temos ainda conhecimento de ofertas de géneros alimentícios a várias casas ou comunidades jesuítas. Na década de 1550, D. João III contribuía para o Colégio de S. Antão de Lisboa com uma tença anual que incluía dez móios de trigo por semana, água e galinhas ${ }^{6}$. Um alvará de 1557 pelo mesmo rei estabeleceu para um período de quatro anos uma tença anual de quatro panacus (cestos) de mandioca, um alqueire de arroz (o arroz podia ser substituído por milho da terra) e um cruzado em dinheiro para cada um dos vinte e oito missionários trabalhando no Brasil. Este privilégio foi alargado aos sete missionários que partiram para a mesma Província em $1559^{7}$.

Os membros das hierarquias política e religiosa locais assumiram igualmente um importante papel no fornecimento de bens alimentares a várias comunidades jesuítas. Cerca de 1554, o Bispo de Portalegre comprometeu-se com os Jesuítas a atribuir vários benefícios à Companhia, entre eles, alguns móios perpétuos de trigo, para tentar convencê-los a dirigir um colégio na mesma cidade ${ }^{8}$. Em inúmeras ocasiões, os Jesuítas em missão sobreviveram graças à oferta de comida e bebida pelos habitantes locais. Naturalmente, tratava-se sobretudo de produtos de origem local ${ }^{9}$.

No topo da hierarquia do sistema organizativo jesuíta local, incluindo o seu sistema alimentar, encontravam-se o reitor e o ministro. Nas regras anexas ao ofício de ministro nas «Reglas Generales sacadas para las Provincias de España y Portugal (1553-1554)» pelo visitador das províncias ibéricas Jerónimo Nadal, devia o reitor, ou, na ausência deste, o ministro, assegurar que as prescrições médicas fossem cumpridas na alimentação dos membros da Comunidade, que a mesa estivesse posta a preceito e que houvesse toalhas para as mãos em número suficiente $^{10}$.

${ }^{5}$ R. Carita, O Colégio dos Jesuítas do Funchal, Funchal, Secretaria Regional da Educação, vol. I, 1987, p. 133.

${ }^{6}$ «Carta de Jerónimo Nadal a Inácio de Loyola, Lisboa, 13 Dezembro de 1553», in Epistolae P. Hieronymi Nadal Societatis Jesu ab anno 1546 ad 1577, ed. F. Cervós, 4 vols., Madrid, Typis Augustini Avrial, 1898-1905, vol. I, 1898, p. 197.

7 «Carta Régia sobre os mantimentos dos Padres do Brazil, Lisboa, 14 de Setembro de 1559», in Monumenta Brasiliae, ed. Serafim Leite, Roma, Monumenta Historica Societatis Iesu, vol. III, 1956, p. 126.

8 «Carta de Tiago Mirão a Inácio de Loyola, Lisboa, 15 de Outubro de 1554», in Epistolae mixtae ex variis Europae locis ab anno 1537 ad 1556 scriptae, nunc primum in lucem editae, ed. V. Agusti, 5 vols, Madrid, Avrial, A. Fortanet, 1898-1901, vol. IV, 1900, p. 397.

${ }^{9}$ A título de exemplo, uma carta escrita pelo P. António Rodrigues aos seus companheiros de Coimbra em 1563, relata, que, ao chegar com os outros Jesuítas a Mato Grosso, os índios tinham-lhes oferecido para comer «avestruzes e outras carnes, que era o que havia na terra». ( «Carta do P. António Rodrigues aos Padres e Irmãos de Coimbra, S. Vicente, 31 Maio de 1563, in Monumenta Brasiliae, vol. II, p. 476)

${ }^{10}$ J. Nadal, «Reglas Generales...», p. 377. 
Um dos aspectos mais característicos da organização do «Comer y Beber Nostro» foi a distribuição entre todos os membros das comunidades jesuítas das várias tarefas inerentes a esta actividade. Antes de mais, a sua realização fazia parte da preparação dos candidatos à Companhia. Em especial, a realização de grande parte destas tarefas cabia aos coadjutores temporais, também designados de oficiais. Tanto na Índia como no Brasil, por norma, os escravos homens ajudavam os hortelãos a cuidar das hortas ou cercas. As mulheres escravas, que no Brasil eram maioritariamente de origem africana, colaboravam essencialmente na cozinha ${ }^{11}$.

Entre os vários oficiais ligados à organização do «Comer y Beber Nostro», destacava-se o cozinheiro. Para além da preparação das refeições, quando não existia um oficial específico, o porcionista, o cozinheiro devia dividir os alimentos em doses individuais, os chamados pratos de porção a distribuir aos comensais.

Cada casa devia ter um único cozinheiro. Na preparação da comida, este podia ser ajudado, não só pelos coadjutores temporais e ainda pelos noviços e escolásticos, como também pelos próprios sacerdotes. Mais precisamente, Juan de Polanco, que era, à data, assistente do Geral Everard Mercurian, ordenou nas «Memoriae Siculae Visitationis 1575-76 -Ordini Dati in diversi collegi della Provincia di Sicilia quali convengono a tutti», que os sacerdotes sem ocupações urgentes e contínuas se deviam ocupar com os ofícios da cozinha e o serviço de mesa $^{12}$.

Um texto anterior, as «Regras para o Colégio de Coimbra (1545-1546)» dános informação valiosa acerca da distribuição das tarefas pelos vários oficiais. Aos refeitoreiros cabia pôr a mesa e tanger a campainha para chamar todos os comensais, avisar os superiores das faltas, cuidar da limpeza da louça e das toalhas de mesa e de mãos, controlar a alimentação dos doentes e a quantidade de pão trazida para as casas jesuítas, assim como o pão que sobrava dum dia para o outro.

O dispenseiro estava encarregado da armazenagem em boas condições de higiene e da correcta distribuição pelo cozinheiro e pelo refeitoreiro dos géneros alimentares, de acordo com as ordens do Mestre da Casa. Neste sentido, o dispenseiro tinha a função de evitar excessos alimentares («que não se passasse a mediocridade»), e que os enfermos recebessem pão e vinho de qualidade ${ }^{13}$.

${ }^{11}$ D. Alden, $o b$ cit., pp. 479-527.

${ }^{12}$ Polanco, «Memoriae Siculae Visitationis 1575-1576 - Ordini Dati in diversi collegi della Provincia di Sicilia quali convengono a tutti», in Polanci complementa: epistolae et commentaria P. Joannis Alphonsi de Polanco addenda caeteris ejusdem scriptis dispersis in his monumentis, ed. D. Restrepo e D. Fernández Zapico, 2 vols, Madrid, Lopez del Horno, 1916-1917, vol. II, 1916, p. 547.

13 «Regras para o Colégio de Coimbra (1545-1546)», In Regulae Societatis Iesu (15401556)..., pp. 44-50. 
O dispenseiro podia ter a ajuda dum porcionista. O segundo oficial devia, entre outras tarefas, assegurar a quantidade de pão trazida do forno, recolher os restos das refeições, ver se seria possível reutilizá-los ou ainda controlar que a adega estivesse em boas condições para a armazenagem do vinho ${ }^{14}$.

Com excepção dos enfermos, que não se podiam levantar da cama, todos os membros da comunidade e convidados eram obrigados a realizar as refeições principais no refeitório. Ademais, a legislação da Companhia procurava evitar que os residentes das instituições jesuítas comessem «fora de casa», em especial, quando frequentavam o noviciado. Mais precisamente, a «Constituição», principal texto legislativo da Companhia de Jesus, determinava que «ninguém saísse de casa nem comesse fora, sem a licença do Superior, a qual, no tempo da provação, não devia ser concedida senão por causas especiais e com companhia segura no juízo do superior» ${ }^{15}$. Um texto manuscrito com instruções para a Província Portuguesa pelo Visitador João Álvares juntou a esta norma a proibição de mais de dois Jesuítas irem jantar a algum mosteiro no dia do respectivo orago $^{16}$.

Seguindo a prática portuguesa, que vigorou até a os finais do séc. XVII, as principais refeições das casas da Companhia eram o jantar e a ceia, refeições essas servidas em dois turnos ou «mesas», na linguagem jesuítica da época. A segunda mesa destinava-se, sobretudo, aos enfermos e às pessoas muito ocupadas e, nos colégios, aos familiares dos alunos ${ }^{17}$.

O horário das duas refeições principais variava, respectivamente, entre as 10 e as 11 horas e as 17 e as 20 horas. No caso de Portugal, o Provincial Simão Rodrigues, na década de 1540, instituiu um horário único durante todo o ano, de acordo com o qual o jantar devia ser servido às 11 e a ceia às 18.30 horas $^{18}$. Em 1579, as refeições nessa província eram já distribuídas segundo dois horários anuais diferentes. De Outubro até à Páscoa, jantava-se às 11 horas e ceava-se às 20 horas. No resto do ano, o jantar era servido às 10 e a ceia era servida às 18 $\operatorname{horas}^{19}$.

De igual modo, tanto na Província da Índia, como na Província do Brasil foram introduzidos um horário de Verão e um horário de Inverno. No Brasil,

${ }^{14}$ J. Nadal, «Reglas generales...», pp. 353-354.

${ }^{15}$ Constitutiones Societatis Iesu, series III, ed. D. Fernández Zapico SJ, 4 vols., Roma, Institutum Historicum Societatis Iesu, 1934-1948, vol. II, P. III, C. II, 1944, p. 156.

${ }^{16}$ IAN/TT, Armário Jesuítico, Livro 5, Visita da Província de Portugal pelo P. João Alvarez, 1610 , fls. 22 e 64.

${ }^{17}$ J. Nadal, «Reglas generales...», p. 358 e IAN/TT, Armário Jesuítico, Livro 5, Visita da Provincia..., fl. 98.

18 «Regras de Simão Rodrigues», in Epistolae P. Paschasii Broeti, Claudii Jaji, Joannis Codurii et Simonis Roderii Societatis Jesu ex autographis vel originalibus exemplis potissimum d, eprompate, Madrid, López del Horno, 1903, p. 831.

${ }^{19}$ IAN/TT, Armário Jesuítico, Livro 5, Visita da Provincia..., fl. 6v. 
durante o Verão, o jantar e a ceia eram respectivamente servidos às 10 horas e às 18 horas. No Inverno, este horário foi atrasado para respectivamente as 11 horas e as 19 horas $^{20}$.

Por sua vez, as «Regras para o Colégio de Goa (1552)» pelo então reitor Gaspar Barzeus, apresentam uma versão diferente do sistema dos dois horários, segundo se tratava de «dias de carne» (dias normais) ou de «dias de peixe» (dias de abstinência). Nos «dias de carne», o jantar e a ceia eram servidos respectivamente às 10 horas e às 17 horas. Nos «dias de peixe», o jantar era servido às 11 horas, mantendo-se o horário da ceia ${ }^{21}$.

Para além das duas refeições principais supra mencionadas, o sistema alimentar jesuíta incluía a possibilidade da merenda e mais raramente do almoço. A merenda consistia em pão, fruta e/ ou uma «talhada de queijo» e era sobretudo destinada aos que se encontravam em recriação nas quintas ou cercas. Por sua vez, o almoço, refeição ligeira que, à época, era tomada logo após o levantar, estava praticamente limitado aos enfermos ou à Quaresma.

\section{RECRIANDO UMA REFEIÇÃO NUM REFEITÓRIO JESUÍTA}

As duas principais refeições eram servidas em pratos individuais, tendo cada comensal um guardanapo, uma faca, uma colher, e um copo individuais ${ }^{22}$. Nas mesas eram objectos obrigatórios jarros de água e de vinho (cada jarro não devia servir para mais de três comensais), ${ }^{23}$ encontrando-se ainda galhetas para o azeite e o vinagre, saleiros, pimenteiros e uma mostardeira.

A louça mais comum era de barro e de madeira, pois tratava-se dos materiais mais económicos. Nas casas jesuítas da Índia, a louça de porcelana era «sem conto», ou seja, muito difundida ${ }^{24}$. Encontrámos ainda inúmeras referências a louça em cobre e estanho. Servia-se a água e o vinho em jarros de vidro ou barro. As galhetas para o azeite e o vinagre eram, por norma, também de vidro.

${ }^{20}$ Archivum Romanum Societatis Iesu (doravante ARSI), Brasil 2, Confirmacion que de Roma se enbia al Pv ${ }^{a}$ del Brasil de algunas cosas que el P.e Christoval de Gouvea Visitador ordeno en ella el año de 1586, fl. 140 e «Informação da Província do Brasil pelo P. José de Anchieta (1585)», in Informações e fragmentos historicos do Padre Joseph de Anchieta, S.J. (1584-1586), pref. C. de Abreu, Rio de Janeiro, Imprensa Nacional, 1886, p. 46.

${ }^{21}$ «Regras de Gaspar Barzeus para o Colégio de Goa (1552)», in Documenta Indica, ed. J. Wicki SJ e J. Gomes SJ, 18 vols., Roma, Institutum Historicum Societatis Iesu, 1948-1988, vol. II, 1950, p. 358.

${ }^{22}$ Em Portugal, o uso dos garfos individuais institucionalizou-se na segunda metade do séc. XVII. R. Amorim, Da mão à boca: para uma história da alimentação em Portugal, Lisboa, Salamandra, 1987, p. 68.

${ }^{23}$ J. Nadal, «Reglas generales...», p. 415 e p. 562.

24 «Enformação das Fortalezas e lugares da India (1568)», in «Duas relações sobre a situação da Índia Portuguesa nos anos de 1568 e 1569», ed. J. Wicki. Studia 8, 1961, p. 143. 
O cozinheiro tinha de ter todas as porções prontas meia hora antes da refeição ser servida. Por sua vez, o refeitoreiro devia aparelhar as mesas no refeitório, pelo menos, uma hora antes do início das refeições. Após ter colocado as toalhas de mesa e de mãos, o refeitoreiro, com a ajuda do dispenseiro, devia colocar na mesa, por esta ordem, o pão, o sal, e os jarros de vinho e da água sobre pratos, para não sujar a mesa ${ }^{25}$. Após o toque da campainha, os comensais deviam sentar-se nos lugares para eles reservados. As instruções do Visitador João Álvarez de 1610 determinavam que o vice-reitor dos colégios ocupasse a cabeceira, seguindo-se, por esta ordem, o conselheiro, os colegiais mais graduados, e quando houvesse alunos com o mesmo grau, a prioridade seria dada aos mais velhos ${ }^{26}$. Os familiares dos colegiais e os enfermos deviam ser servidos em mesas separadas ${ }^{27}$.

Em 1553, os Jesuítas da Assistência Lusitana introduziram a prática monacal de tomarem as refeições em silêncio e acompanhadas pela leitura de livros sacros. Após terem terminado a refeição, os comensais deviam levantar-se da mesa, não esperando que os companheiros terminassem de $\operatorname{comer}^{28}$.

Em especial, nas missões, os rituais de alimentação caracterizavam-se por aspectos de segregação ou discriminação. No Colégio de S. Paulo de Goa os estudantes europeus comiam em mesas distintas dos estudantes asiáticos, sendo os primeiros beneficiados com meio pão a juntar à porção individual ${ }^{29}$.

A Festa de S. Inácio a 31 de Julho era o momento alto do ano litúrgico jesuíta, inclusive do ponto de vista gastronómico. Até à expulsão dos Jesuítas de Portugal e das suas possessões coloniais em 1759, as casas portuguesas tinham por costume enviar um prato de arroz doce aos príncipes e às princesas. Dada a importância da mesma festividade, por vezes, eram contratados cozinheiros externos ${ }^{30}$.

${ }^{25}$ J. Nadal, «Reglas Generales...», p. 451.

${ }^{26}$ IAN/TT, Armário Jesuítico, Visita da Província..., fl. 7.

27 J. Nadal, «Instruções para a Província Lusitana (1561)», in Epistolae P. Hieronymi Nadal..., vol. IV, p. 200 e «Dois compêndios das ordens dos padres gerais e congregações provinciais da Província dos Jesuítas de Goa feitos em 1640», ed. J. Wicki, Lisboa, Centro de Estudos Históricos Ultramarinos, 1982, p. 361.

28 «Regras de S. Inácio (1549)», in Regulae Societatis Iesu (1540-1556)..., p. 196 e F. Martins, A Arquitectura dos primeiros colégios jesuítas de Portugal (1542-1759): cronologia, artistas, espaços, 2 vols., tese de doutoramento. Porto, Faculdade de Letras da Universidade do Porto, 1994, vol. I, p. 911.

${ }^{29}$ «Regulamentos do Colégio de Santa Fé, Goa, 15 Agosto 1597», in Documenta Indica..., vol. XVIII, 1998, p. 823.

${ }^{30}$ IAN/TT, Cartório dos Jesuítas, Livro 4, Livro de Despesa do Colégio de Setúbal 17321752 , fl. $124 \mathrm{v}$. 
PRINCÍPIOS FUNDAMENTAIS DO «COMER Y BEBER NOSTRO»: DISCIPLINA RELIGIOSA E PREOCUPAÇÃO COM A SAÚDE; A APLICAÇÃO MODERADA DO VOTO DA POBREZA E DE PRÁTICAS DE ABSTINÊNCIA O PRINCÍPIO DA LIMPEZA

À semelhança de todas as ordens religiosas, os Jesuítas fazem um voto de pobreza. Por isso, as Constituições dizem que «o comer, o beber, o vestir, o calçar e o dormir devem ser como coisas de pobres» ${ }^{31}$. No calendário mensal jesuíta existia, aliás, o chamado Dia da [Santa] Pobreza ${ }^{32}$. Gostaríamos ainda de referir as frequentes admoestações feitas pelas hierarquias aos Jesuítas para não convidarem pessoas de fora para dormir ou comer. Eram igualmente os Jesuítas frequentemente advertidos para manterem o mesmo espírito de pobreza, quando recebiam hóspedes, inclusive os mais ilustres. A pobreza devia ser respeitada, mesmo quando o Rei de Portugal era convidado a partilhar as refeições dos membros das casas jesuítas ${ }^{33}$.

As festas privadas de Jesuítas, durante as quais se serviam doces feitos em casa ou oferecidos, as merendas de marmelada e outros doces e ainda o costume de se guardar alimentos e louça e talheres em prata no interior dos cubiculae eram costumes considerados perniciosos, e que foram, por isso, objecto de crítica local e preocupação por parte da hierarquia romana. A frequência de tais avisos constitui, no entanto, claro indício do pouco sucesso do controlo destes hábitos.

Segundo Carlos Veloso, em Portugal, na Idade Moderna, os dias oficiais de abstinência de carne equivaliam a cerca dum terço do total dos dias do $\operatorname{ano}^{34}$. A questão da abstinência é obviamente tanto mais pertinente, quando se trata de comunidades religiosas. No caso da Província Portuguesa da Companhia de Jesus, as «Regras para o Colégio de Coimbra (1545-1546)» determinaram que, nos dias oficiais de abstinência, a alimentação dos membros da comunidade se devia limitar à ceia a um só alimento, ou seja, pão, fruta ou um alimento seleccionado pelo mestre da casa. Nos dias de abstinência particular, como sextas-fei-

${ }^{31}$ Constitutiones Societatis Jesu (1944), vol. II, Ex. Gen., C. IV, pp. 64-65.

${ }^{32}$ No Noviciado de Coimbra os comensais recebiam nesse dia um pão com dois ou três dias, «o qual, além de ser pequeno, por ser negro, \& de mão sabor, causava boa mortificação». Ver A. Franco, Imagem da Virtude em o Noviciado da Companhia de Jesus no Real Collegio de Jesus de Coimbra em Portugal na qual se contem as vidas, \& sanctas mortes de muitos homens de grande virtude, que naquela Sancta caza se criaram, Évora, Officina da Universidade, 1719, p. 11.

33 «Instrução do Geral Diego Lainez ao Provincial de Portugal Luís Gonçalves da Câmara, Roma, 4 de Dezembro de 1560», in Lainii monumenta, Epistolae et acta Patris Jacobi Lainii ex autographis vel originalibus exemplis deprompta, a Patribus eiusdem Societatis edita, 8 vols., Madrid, Lopez del Horno, 1912-1917, vol. V, 1915, p. 320.

${ }^{34}$ Carlos Veloso, Os sabores da Expansão - Continuidade e ruptura nos hábitos alimentares portugueses, Turres Veteras IX - Actas do Encontro História da Alimentação, Lisboa, Edições Colibri, 2007, p. 129. 
ras e sábados, não era permitido servir-se a ceia, salvo com licença especial ${ }^{35}$. Nadal, nas «Reglas Generales» de 1553-1554, autorizou o consumo dum pouco de vinho com a ementa estabelecida nas «Regras» de Coimbra ${ }^{36}$.

Para além das épocas e dos dias oficiais de abstinência e jejum, eram comuns os castigos em forma de privações ou da redução substancial de alimentos. Nas «Primeiras Regras para as Escolas» (data desconhecida) por Inácio de Loyola, o castigo para os alunos que usassem o vernáculo seria no dia seguinte não beberem vinho à refeição ou não comerem carne à noite. Só se daria carne aos desobedientes com licença do superior ${ }^{37}$. Jerónimo Nadal referiu outros tipos de penitências relacionados com a alimentação, e que eram jejuns de pão e água, comer em mesas baixas, extrair algum alimento da refeição, pedir licença cada vez que se quisesse beber um trago de vinho ou água, confessar a própria culpa sempre que se bebesse, e ainda fazer uma oração no refeitório perante a comunidade $^{38}$.

Simultaneamente, razões práticas, entre as quais se destacavam o cumprimento do famoso quarto voto de ir em missão por decisão do Papa e a conservação da saúde, estiveram na origem da preocupação de que todos os membros das comunidades jesuítas recebessem alimentação suficiente em quantidade e em qualidade. Neste sentido, as «Constituições para os Colégios (1549-1550)» prescreveram que os alimentos não deviam ser contrários, mas convenientes à saúde, isto é, de bom mantimento e digestão, e em quantidade bastante para manter as forças e não pesar em demasia no estômago ${ }^{39}$.

A mesma preocupação reflectiu-se em instruções prescrevendo a isenção ou a moderação de jejuns e abstinências. A Quaresma era a única altura do ano em que os jovens de idade inferior a vinte e um anos estavam autorizados a jejuar, e só depois de terem sido observados por um médico e com atenção à saúde. Deviam os mais jovens não só almoçar, como ainda merendar com discrição, de modo a serem ajudados na saúde e nos estudos, em especial durante o Verão. Foi ainda interdito aos mais jovens o costume muito enraizado de fazerem penitências de água e pão ${ }^{40}$.

As condições climáticas das missões aconselhavam a moderação das abstinências. Em 1560, o Geral Diego Lainez aconselhou o Provincial da Índia, António Quadros, caso este assim o entendesse, a isentar os seus companheiros

35 «Regras para o Colégio de Coimbra...», p. 46.

${ }^{36}$ J. Nadal, «Reglas generales...», p. 520.

${ }^{37}$ Loyola, «Primeiras Regras para as Escolas», in Regulae Societatis Iesu..., p. 10.

38 J. Nadal, «Reglas Generales...», pp. 234-235 e p. 520.

39 «Constituições para os Colégios», in Regulae Societatis Iesu (1540-1556), pp. 234-235.

40 «Carta de Juan de Polanco por comissão de Inácio de Loyola a André de Oviedo e Nicolás de Bobadilla, Roma, 17 de Janeiro de 1552», in Epistolae et instructiones / Ignacio de Loyola, 12 vols, Madrid, Typis G. López del Horno, 1966-1968, vol. IV, 1966, pp. 105-107. 
da abstinência de sexta-feira, assim como a permitir que se bebesse água durante o dia, por conselho médico ${ }^{41}$.

Em especial, limitações e isenções de práticas de abstinência foram instituídas para os missionários em viagem. Foram desaconselhados os longos jejuns a bordo. Deviam os reitores considerar a possibilidade de dispensarem os missionários, que estivessem para embarcar, da realização de abstinências ${ }^{42}$.

O princípio da limpeza era o outro princípio identificador do sistema do «Nostro Comer y Beber». Diziam as «Regras do Refeitoreiro para o Colégio Romano» (segunda metade do séc. XVI), que o refeitório e todos os objectos deviam estar tão limpos, quanto possível, e que não faltasse água para lavar as mãos, nem toalhas de mão distintas para os sacerdotes e os restantes convivas. Devia-se proceder todas as semanas à troca das toalhas de mesa, enquanto os guardanapos individuais deviam ser entregues para serem lavados duas vezes por semana pelos próprios comensais ${ }^{43}$.

Naturalmente, a preocupação com a limpeza encontrou eco entre os responsáveis das casas nas províncias jesuítas da Assistência Portuguesa. No Colégio da Purificação de Évora, as toalhas de mesa deviam ser substituídas duas vezes por semana (à Quarta-Feira e ao Domingo), enquanto os guardanapos deviam ser mudados três vezes por semana ${ }^{44}$. Também as «Regras para o Colégio de Goa (1552)», por Gaspar Barzeus determinaram que as toalhas para as mãos e para a mesa e os guardanapos fossem mudados duas vezes por semana ${ }^{45}$. As «Regras para o Colégio de Coimbra (1545-1546)» ${ }^{46}$ eram mais severas no que respeitava à limpeza. Tanto as toalhas para as mesas, como as toalhas para as mãos e de cozinha, deviam ser mudadas três vezes por semana, mais precisamente ao Domingo, à Terça-Feira e à Sexta-Feira.

As «Reglas Generales» de Nadal supra referidas continham importantes prescrições adicionais para a manutenção da limpeza na cozinha e no refeitório. O cozinheiro devia preocupar-se em manter a cozinha sempre limpa, deitando fora as imundicies. Devia manter faqueiros e louça de cozinha em perfeito estado de limpeza. Precisou ainda o mesmo texto, que o cozinheiro devia limpar ou fazer limpar os pratos, escudelas, lâminas e outros instrumentos diariamente, e que fossem esfregados com mais cuidado ao fim de semana ${ }^{47}$.

${ }^{41}$ J. Wicki, «Auszüge aus den Briefen der Jesuitengeneräle an die Obern in Indien (15491613)», Archivum Historicum Societatis Iesu, vol. 22, 1953, p. 117.

${ }^{42}$ IAN/TT, Armário Jesuítico, Livro 5, Visita da Província..., fl. 51.

${ }^{43}$ A. D'Ambrosio e M. Spedicato, Cibo e clausura: regimi alimentari e patrimoni monastici nel Mezzogiorno moderno, Bari, Cacucci, 1998, p. 104-

${ }^{44}$ IAN/TT, Armário Jesuítico, Livro 5, Visita da Província..., fl. 6v.

45 «Regras de Gaspar Barzeus...», p. 360.

46 «Regras para o Colégio de Coimbra...», pp. 42 e 46.

${ }^{47}$ J. Nadal, «Reglas generales...», p. 448. 
Por sua vez, o refeitoreiro, que estava encarregado da limpeza do refeitório e das mesas, foi incumbido de assegurar, que o refeitório fosse varrido duas vezes ao dia, que as mesas fossem limpas entre os dois turnos das refeições, e que as toalhas para as mãos (os sacerdotes e os leigos deviam ter toalhas em sítios diferentes) e os copos de barro e estanho fossem guardados limpos ${ }^{48}$.

\section{A PREFERÊNCIA POR UM REGIME ALIMENTAR RICO E VARIADO}

A proporção e a variedade da comida consumida por cada comunidade variou bastante ao longo dos tempos. Todavia, sempre que possível, as casas da Companhia seguiam padrões de qualidade e variedade no seu regime alimentar.

A questão da qualidade das ementas relaciona-se com a natureza da própria Companhia de Jesus. Dado o seu carácter missionário-apostólico, a legislação da Companhia reforçou a necessidade dos seus membros receberem alimentação suficiente para melhor realizarem as suas tarefas ad maiorem Dei gloriam.

Outras vezes, episódios, como a da troca dos vinhos produzidos localmente pelo Colégio de Braga por vinhos «mais cheirantes» de Lamego ou da venda de queijos para, em troca, serem comprados queijos do Alentejo pelo Colégio de S. Antão constituem prova evidente da preferência pela qualidade em si mesma ${ }^{49}$.

Nas «Reglas Generales» de Jerónimo Nadal o «Comer y Beber Nostro» devia incluir pão, água, um pouco de vinho, um pouco de carneiro ou peixe, e sopa. As refeições deveriam ser iniciadas, e, sobretudo, terminadas com alimentos de proveniência local ${ }^{50}$.

As duas principais refeições -o jantar e a ceia- eram antecedidas pelo antipasto, espécie de aperitivo, que desapareceu en Portugal, mas se mantém em Itália ${ }^{51}$.

Era ainda o antipasto prescrito para os membros das comunidades jesuítas, quando se encontravam em recreação nas cercas. ${ }^{52} \mathrm{~A}$ sua composição era varia-

\footnotetext{
${ }^{48}$ Ibidem, p. 465.
}

${ }^{49}$ F. Martins, ob. cit., vol. I, p. 915 e IAN/TT, Cartório dos Jesuítas, Livro 5, Livro de Receitas e Despesas do Colégio de S. Antão (1628-1654), fl. 23.

${ }^{50}$ J. Nadal, «Reglas Generales sacadas para las Provincias de España y Portugal» (15531554)», in Regulae Societatis Iesu (1540-1556), ed. D. Fernández Zapico, Roma, Typis Pontificae Universitatis Gregorianae, 1948, p. 377.

${ }^{51} \mathrm{O}$ antipasto era considerado um elemento tão importante nas refeições das casas jesuítas, que o Geral Francisco de Borja mostrou grande preocupação com o abandono da sua prática no Colégio de Évora, e tentou que a mesma prática fosse reintroduzida na instituição. Ver «Carta de Francisco de Borgia a Leão Henriques, Roma, 9 de Janeiro de 1567», in Sanctus Franciscus Borgia quartus Gandiae dux et Societatis Jesu praepositus generalis tertius/ Epistolae et acta (1894-2003), 6 vols., Madrid et al, Avrial et al., vol. IV, 1910, p. 371.

${ }^{52}$ F. Martins, ob. cit., vol. I, 1994, pp. 944-945. 
da. Podia ser uma peça de fruta (em Goa, o antipasto era um figo) ${ }^{53}$ pão, peixe, carne, ovos, legumes, doces.

A carne, o alimento mais oneroso dos cardápios na Idade Moderna, era consumida fresca, salgada, seca, em conserva e ainda en fumados (presunto) e enchidos (salpicão, salsicha, chouriço, linguiça). Entre os tipos mais comuns de carnes, encontravam-se a vaca, o porco, que era talvez a qualidade de carne mais consumida na Europa por todas as camadas sociais, a galinha e o carneiro (carnes dadas aos achacados ou enfermos $)^{54}$. Encontrámos ainda a referência a caça, sobretudo, lebre e perdiz, que eram acessíveis apenas às elites ${ }^{55}$.

O consumo autorizado de carne variou ao longo do tempo e para as várias casas. Inicialmente, a dose diária autorizada de carne para os Jesuítas em Roma era de cerca de 413 gr., aumentada posteriormente para c. 550 gr., por razões de natureza médica ${ }^{56}$ Dado a experiência ter demonstrado que a primeira prescrição dada pelo Visitador Nadal de c. $248 \mathrm{gr}$ de carne (5 onças) para o Colégio de Coimbra era demasiado reduzida, foi decidido localmente aumentar a dose para

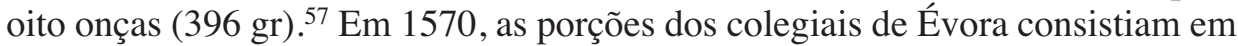
$680 \mathrm{gr}$ de carne de vaca ou de porco. No início do séc. XVII, as porções (carne de vaca ou de boi, ou ambas) dos colegiais de Évora perfaziam 474gr. Na mesma época, o Provincial do Brasil estipulou a quantidade da ração de peixe ou carne em 450gr para o jantar de Inverno e 300gr no Verão. Um século mais tarde, a porção ou dose de carne para os alunos de S. Antão, Lisboa, era 450gr de carne de vaca ou de carneiro e $45 \mathrm{gr}$ de toucinho ${ }^{58}$.

Devido ao grande número de dias de abstinência antes mencionado e à abundância de peixe em Portugal e no Brasil, este alimento ocupava um lugar significativo nas dietas das casas da Companhia de Jesus em estas duas regiões. Por outras palavras, abstinências rigorosas determinaram, assim, um grande consumo de peixe entre as várias comunidades. Exemplarmente, a alimentação dos candidatos à Missão do Brasil consistia ordinariamente em peixe seco, sardinha e bacalhau (estes dois peixes eram então os últimos mais baratos). A carne era apenas autorizada em dias de festa.

A carne e o peixe podiam ser servidos com uma escudela de arroz e ou de legumes frescos (hortaliça, chicória, abóbora) e secos (feijão, lentilhas, tremoço).

53 «Regulamentos do Colégio de Santa Fé...», p. 823.

${ }^{54}$ Divulga-se nessa época a canja de galinha enquanto ementa para os doentes. A palavra canja vem precisamente da palavra indiana canjica (caldo de galinha, arroz ou trigo). (S. R. Dalgado, Glossário Luso-Asiático, 10 vols, Lisboa, Academia das Ciências, 1983, vol. I, p. 206).

${ }^{55}$ K. Albala, Food in Early Modern Europe, Westport (CT), Greenwood Press, 2003, p. 62.

56 «Carta de Inácio de Loyola a Francesco Palmio, Roma, 16 Maio 1554», in Epistolae et instructiones..., vol. VII, p. 7.

57 «Carta de Tiago Mirão a Inácio de Loyola, Coimbra, finais de 1554», in Epistolae Mixtae..., vol. IV, p. 550.

${ }^{58}$ D. Alden, ob. cit., p. 627. 
Em Portugal, a carne e o peixe eram condimentados com azeite, vinagre, ou mos$\operatorname{tarda}^{59}$ e uma cada vez maior quantidade e variedade de especiarias ${ }^{60}$. No Brasil, o leite substituía, com frequência, o vinagre e o azeite, enquanto condimento da carne ou do peixe, devido à escassez dos dois primeiros géneros.

Acompanhando a tendência europeia coeva, verifica-se que nas casas jesuítas em Portugal e nas missões, a manteiga, que era adquirida crua ou cozida, substituiu, cada vez mais, o azeite para fritar os alimentos ${ }^{61}$.

As refeições terminavam com fruta, queijos ou doces. No que se refere aos queijos, na documentação, são mencionados queijos frescos, requeijão, e, sobretudo, os muito apreciados queijos do Alentejo, às vezes, distinguidos entre queijos de Serpa ou de Évora, os queijos da Serra da Estrela, à época, considerados já os queijos por excelência, e ainda os queijos flamengos ou queijos holande$\operatorname{ses}^{62}$.

O gosto jesuíta acompanhava o gosto nacional pelos doces, destacando-se, nas ementas dos Jesuítas portugueses, os doces secos, o o pão de ló, ou o arroz doce. Os Jesuítas contribuíram ainda decisivamente para o sucesso das compotas ou marmeladas de frutas nas missões. Em especial, no Brasil, dedicaram-se, desde cedo, à produção e à exportação de marmeladas feitas com frutos cultivados nas suas cercas.

As principais bebidas eram a água e o vinho, ocasionalmente uma chávena de chocolate ${ }^{63}$. O vinho mais apreciado era o vinho de Lamego exportado pelos Jesuítas até às longínquas missões do Japão, seguindo-se os vinhos de Lagoa, de Carcavelos e de Campolide.

Para colmatar a crónica escassez de vinho ou o seu preço proibitivo, na Índia, como no Brasil, era comum o recurso a vinho «baptizado» com água, assim como a bebidas locais. No Brasil, quando rareava o vinho, bebia-se vinho com mel (o consumo desta mistura era também comum em Portugal), bebidas alcoólicas extraídas do caju (o «cavim») ou do ananás, ${ }^{64}$ ou água cozida com milho e misturada com mel. Na Índia, os jesuítas aderiram rapidamente à longa

\footnotetext{
${ }^{59}$ A mostarda, produto já mencionado por Gil Vicente, enquanto condimento para carnes assadas, era no séc. XVI também um substituto do azeite e do vinagre na condimentação do peixe.

${ }^{60}$ I. Drummond Braga et. al., «A Vida Quotidiana», In Nova História de Portugal, coord. A. H. Oliveira Marques, vol. V, coord. J. J. Alves Dias, Lisboa, Presença, 1998, p. 621.

${ }^{61}$ Albala provou que, na Idade Moderna, a manteiga é um alimento cada vez mais importante nos livros de cozinha e nas regras de culinária (K. Albala, The banquet: dining in the great courts of late Renaissance Europe, Urbana e Chicago, University of Illinois Press, 2007, p. VIII).

${ }^{62}$ C. Veloso, ob. cit., p. 122.

${ }^{63}$ D. Alden, ob. cit., p. 627.

${ }^{64}$ F. Cardim, Tratados da terra e gente do Brasil, ed. A. M. de Azevedo, Lisboa, Comissão Nacional para as Comemorações dos Descobrimentos Portugueses, 2000, p. 91 e p. 115 e J. E. Ferrão, A aventura das plantas e os descobrimentos portugueses, Macau, Comissão Territorial de Macau para as Comemorações dos Descobrimentos Portugueses/ Fundação Macau, 1996, p. 85.
} 
tradição local de beber um «vinho» ou «aguardente» destilada a partir da palmeira, a «araca» ou «uraca», ou do coco, a «sura ${ }^{65}$.

\section{COMER NA MISSÃO: DO INFERNO AO PARAÍSO}

Os relatos abundam em referências à escassez alimentar vivida por Jesuítas, sobretudo, nas missões fora da Europa. Porventura, como aconteceu em 1635 em Pernambuco, as casas e as cercas eram assaltadas, originando constrangimentos alimentares. Um jesuíta chamado Ferreira diz-nos que, nessa ocasião, os Holandeses levaram consigo a totalidade do milho e da mandioca, assim como os animais (vacas, ovelhas e galinhas) da cerca. A alimentação dos habitantes da casa passou a consistir única e exclusivamente em feijão sem sal ${ }^{66}$.

Simão de Vasconcelos, cronista da Província do Brasil do séc. XVII, descreveu do seguinte modo os difíceis começos da Companhia de Jesus nesta região: «Pera mesa vsáraõ algum tempo de folhas largas de aruores em lugar de guardanapos; mas bem se escusauão toalhas, onde faltava o comer, o qual não tinhão donde lhes viesse, se não dos Indios, que lhes davam alguma esmola de farinha, e às vezes (mas raras) alguns peixinhos do rio, \& caça do matto. Muito tempo passarão grande fome, $\&$ frio» ${ }^{67}$.

A vida parece ter sido igualmente muito dura para os Jesuítas em algumas zonas do Oriente. Na Costa da Pescaria no Sul da Índia, a alimentação dos missionários consistia essencialmente em biscoito duro, já que, por norma, o pão escasseava, assim como a carne. Já em finais do séc. XVII, o P. Cinnami, missionário em Mysore, testemunhou que a sua alimentação ordinária se limitava a arroz, legumes, leite, manteiga e água ${ }^{68}$.

As queixas mais comuns por parte dos missionários e do ponto de vista da alimentação eram a falta de pão de trigo, de sal, de azeite, e ainda de vinho. De acordo com uma extensa carta escrita por Brás Lourenço aos padres e irmãos de Coimbra (1554), durante uma expedição, ele e os seus companheiros, quando não tinham que comer, que era a maior parte do tempo, comiam abóboras oferecidas pelos índios e cozidas sem sal e sem azeite, com farinha de guerra (farinha feita com mandioca) podre. Comiam de alguidares e recipientes, nos quais os índios tinham cozinhado antes carne humana. Tal facto criava asco no autor, ao qual, todavia, rapidamente se sobrepunha a fome. Muitas vezes, não se celebrava missa, devido à falta de vinho ${ }^{69}$.

65 «Carta de Thomas Stephen aos companheiros na Europa, Goa, 10 de Novembro de 1579», In Documenta Indica..., vol. XI, p. 690.

${ }^{66}$ ARSI, Brasil 8, Carta de Ferreira SJ, Pernambuco, 10 de Junho de 1635, fl. 483.

${ }^{67}$ Simão Vasconcelos, Chronica da Companhia de Jesus do Estado do Brazil, Lisboa, Typ. do Panorama, 1865, pp. 133-134.

${ }^{68}$ D. Alden, ob. cit., p. 627.

${ }^{69}$ «Carta de Brás Lourenço aos Jesuítas de Coimbra, Espírito Santo, 26 de Março de 1554», in Monumenta Brasiliae..., vol. II, p. 45 e p. 48. 
Em 1577, Belchior Coelho considerava que a falta de alimentos era uma das duas principais causas (a segunda era o excessivo número de missionários) para as «desinquietações» que se verificavam no Brasil. Nas suas palavras, «em todo o Brasil se não come pão nem bebe vinho salvo que aos Padres e alguns Irmãos se daa a cada hum, hum copo de vinho já agoado, como são pouco mais ou menos os de Roma. Isto se faz dalguns annos a esta parte, que dantes se fazia a menos e aguora se não faz ainda a todos. Pão, como diguo, não se come salvo em Pernãobuco, aonde por estar mais ao perto de Portugal e ter muitos mercadores e gente que come pão, as devotas mãodão algumas vezes alguma esmola de pão, e outro, que se compra, de maneira que algumas vezes se põie a terça parte d'hum pão dos de cá, mas não a todos. E simpliciter se pode dizer que se não come pão nem bebe vinho. Carne não na há sufficiente senão em a Bahia. Geralmente fallando, se padece muito no comer, assi polla falta que há, como polla qualidade dos comeres, que todos os do Brasil são insipidos e sem sostancia» ${ }^{70}$.

No entanto, os missionários da Companhia souberam rapidamente ultrapassar muitas dificuldades alimentares colocadas pela missão. Desde o início da presença jesuíta fora da Europa, a acomodação gastronómica foi uma constante. Depreende-se da documentação que muitos missionários jesuítas apreenderam rapidamente a valorizar os produtos locais na sua alimentação. Em particular, no que toca ao Brasil, os relatos dos missionários mostram um consumo cada vez maior dos produtos locais, motivado por uma percepção mais positiva das suas qualidades. Na visão jesuíta, os produtos locais ganhavam, com frequência, a melhor nas comparações estabelecidas com os produtos europeus, tanto do ponto de vista da saúde, como do gosto. Afirmou o jesuíta português Rui Pereira em 1560 «Se houvesse paraíso na terra, eu diria que agora o havia no Brasil. Saude nao ha mais no mundo: ares frescos, terra alegre... Muitas galinhas e mais baratas que em Portugal. Carneiros caçando nos matos e de boa carne, vinho, água, pão fresco, farinha da terra mais saudável que o pão de Portugal. Produtos muito abundantes e dando-se todo o ano sem se plantarem $»^{71}$.

Apenas chegado ao Brasil, Manuel da Nóbrega afirmou, em 1549, que o pão de mistura de milho e trigo feito na Baía escusava o pão de trigo português ${ }^{72}$. A mesma opinião era partilhada por Baltasar Fernandes, que escreveu, em 1567, que «o pão de Piratininga era tão bom que não alembrava o pão do Reino» ${ }^{73}$.

70 «Enformação dalgumas cousas do Brasil» [por Belchior Cordeiro, 1577]», ed. Serafim Leite, Anais da Academia Portuguesa de História, vol. 16, 1965, pp. 194-195.

${ }^{71}$ «Carta de Rui Pereira aos Padres e Irmãos de Portugal, Baía, 15 de Setembro de 1560», in Monumenta Brasiliae..., vol. III, p. 272.

${ }^{72}$ Nóbrega, «Informação das Terras do Brasil para os padres e irmãos de Coimbra (1549)», in Monumenta Brasiliae..., vol. II, 1956, p. 148.

73 «Carta de Baltasar Fernandes aos padres e irmãos de Portugal, Piratininga, 5 de Dezembro de 1567», in Monumenta Brasiliae..., vol. IV, p. 424. 
Em particular, o peixe do Brasil teve uma percepção favorável por parte dos europeus, nomeadamente no que se refere ao tema da saúde. Escreveu Fernão de Cardim, no início do séc. XVII, que todo o peixe do Brasil «era saudável, não causando nem sarna, nem outras enfermidades, como na Europa, sendo antes alimento dos enfermos de cama. O peixe-boi era o peixe mais apreciado, pois era muito sadio e, salgado ou fresco, de muito bom gosto. Parecia mais carne de boi $\gg^{74}$.

Embora a tartaruga fosse já usada na culinária da Europa de Quinhentos, foi todavia no Brasil que este animal se tornou um alimento muito popular entre os europeus. Proporciona-nos o P. António Vieira, na célebre carta ao Provincial do Maranhão de 1654, uma descrição muito detalhada da percepção gustativa por parte dos europeus e do valor nutricional atribuído a vários tipos de tartarugas, assim como do uso culinário dado aos seus ovos: «Os Portugueses as mandam buscar aqui e as teem por comer regalado, e a mesma informação nos deu também o Padre Manuel de Sousa, o qual está já tão grande prático, (...). Ele é o que menos estranha esta diferença de manjar. A carne é como a de carneiro, e se fazem dela os mesmos guisados, que mais parecem de carne que pescado. Os ovos são como os de galinha na cor, e quase no sabor, a casca mais branca e de figura diferente, porque são redondos, e deles bem machucados se fazem em tachos as belas manteigas do Pará. Afora estas tartarugas do mar, a que são inferiores, a que os Índios chamam de viração, e de ordinário magras, há outras criadas em lagos e mortas com arpões nas pontas das flechas, e estas são as mais singulares, como também outra espécie, que sempre vive em terra, que em as Índias de Castela se chamam «icotêas» e aqui jabotís, que é sustento muito geral em tôdas estas partes, e foram os que nesta jornada nos mataram muitas vezes a fome. Nascem estes jabotís e vivem sempre na terra, sem nunca entrarem no mar, nem nos rios, e contudo estão julgados por peixe, e como tais se comem nos dias em que se proíbe a carne, por se ter averiguado que teem o sangue frio» ${ }^{75}$.

Sem dúvida, o contributo jesuíta para o enriquecimento das dietas alimentares na Época Moderna passou assim pela introdução e pela difusão de produtos alimentares nas dietas dentro e fora da Europa. Terá sido o caso do cajueiro originário do Brasil, que terá sido transplantado pelos Jesuítas para a Índia entre 1563 e 1578. De igual modo, os Jesuítas terão sido os pioneiros na importação de chocolate para a Europa. Em 1674, o missionário Bethencourt promoveu da cultura do cacau no Maranhão com sementes levadas da Baía ${ }^{76}$.

${ }^{74}$ F. Cardim, ob. cit., p. 29 e J. E. Ferrão, ob. cit., pp. 128-129.

75 «Carta de António Vieira ao Provincial do Brasil, Francisco Gonçalves, Maranhão, 1654», in Cartas de António Vieira, ed. J. L. Azevedo, Lisboa, IN-CM, 1997, vol. I, pp. 258-259.

${ }^{76}$ Ferrão, ob. cit., p. 80 e pp. 85-86 e L. Prosperi, Il cibo del piacere e dell'immortalità: dietetica e procreazione in antico regime (Francia, sec. XVI-XVII), tese de doutoramento. Florença, Instituto Universitário Europeu, 2006, p. 253. 


\section{CONCLUSÕES}

Para concluir, os Jesuítas tiveram um papel fundamental no enriquecimento da gastronomia dentro e fora da Europa, tanto em termos teóricos, como sobretudo práticos.

Sempre que as condições locais o permitiam, os Jesuítas procuraram seguir um sistema alimentar variado. Por um lado, pretendia-se, com isto, melhor responder ao princípio fundamental da conservação da saúde. Por outro lado, reflectem os hábitos alimentares jesuítas em Portugal, na Índia e no Brasil durante os sécs. XVI a XVIII, a divulgação do consumo de produtos antes desconhecidos de origem não europeia.

Como é inerente ao conceito de «Modo Nostro», o «Comer y Beber Nostro», em Portugal, na Índia e no Brasil, durante a Época Moderna, foi largamente determinado pela preocupação das hierarquias locais e centrais (legislação e introdução de membros com a incumbência de realizar tarefas específicas dentro do sistema organizativo alimentar) determinarem ao pormenor e duma forma o mais uniforme possível todo o ciclo ou sistema alimentar dos membros da Companhia de Jesus em todos os locais onde estes viviam.

Todavia, os diferentes contextos locais significaram, com frequência, alterações notórias (entre eles a introdução dum terceiro horário na Índia) do «Nostro Modo», no que se refere ao «Beber y Comer Nostro». A acomodação alimentar dos Jesuítas vivendo e trabalhando em zonas, muitas vezes, trazidas por eles ao conhecimento dos europeus, resultou não só dos constrangimentos locais (escassez e preços elevados de determinados produtos, distintos costumes e hábitos das populações), como do «Modo Nostro» aplicado ao «Nostro Comer y Beber». Ou seja, as autoridades, na sua actividade legisladora, incluíam sempre licenças e dispensas das normas gerais, visando, com isso, melhor responder à diversidade local.

Finalmente, algumas práticas do «Comer y Beber Nostro» (entre elas, a prática comum do convite de hóspedes ou refeições demasiado lautas, e, por isso, inadequadas ao espírito de pobreza jesuíta), mostraram-se inadequadas. Pela mesma razão, as autoridades procuraram limitá-las, som qualquer êxito, como se depreende pela repetição das ordens em contrário. 